\title{
Double-arm steel connector of glass façades
}

\author{
Izabela Major ${ }^{*}$, Maciej Major and Zbigniew Respondek \\ Czestochowa University of Technology, Faculty of Civil Engineering, Akademicka Street 3, 42-200 \\ Częstochowa, Poland
}

\begin{abstract}
This paper presents a numerical analysis of a steel double-arm connector, according to the authors' solution, designed for fixation of glass façades. The analysis was carried out in order to obtain a distribution of stresses and displacements, on the basis of which global displacements and maximum stresses were determined. An additional element of the solution was the use of the M8 bolt, as a linking element of the steel walls of both arms. The numerical simulation was performed using the ADINA program, which is based on the finite element method (FEM). The dynamic effect of wind gusts on the glass façade was assumed, taking into account both wind pressure and suction. The adoption of a rectangular element of the glass façade causes an unfavorable load distribution at the connection point. The conducted research allowed to determine displacements and stresses in a steel connector made of S355JR steel. The applicability of the proposed solution for glass façades with a height of up to $100 \mathrm{~m}$ has been demonstrated.
\end{abstract}

\section{Introduction}

Due to the development of technologies related to the improvement of thermal and mechanical properties of building glass, glass façades have become one of the most characteristic elements of urban development. Having such a façade has become a kind of determinant of the prestige of a company, institution or commercial facility. Glass as a material still fascinates architects and constructors [1]. It stands out from other building materials with aesthetics, good resistance to environmental factors and, above all, light transparency. The use of glass as a component of building partitions thus fills the natural need for human eye contact with the external environment and provides natural illumination of rooms. Modern glazing, thanks to the use of ultra-thin coatings, has good thermal insulation, protects rooms from excessive heat gains and shapes the colouring of the façade.

Annealed (not modified) glass, however, has some drawbacks. It is a material that is almost perfectly stiff and therefore brittle. Its tensile and bending strength is many times less than compressive strength. Particularly sensitive to impact and spot loadings (no possibility to relieve stress by local yielding) Glass has a disordered atomic structure (like liquid), so that between the atoms are free spaces, so-called microcracks. They tend to expand under load, therefore the glass has several times less tensile strength for long-term

\footnotetext{
* Corresponding author: imajor@bud.pcz.czest.pl
} 
loads than for short-term loads. The areas most vulnerable to cracking are the ones near the edges of glass panes (especially when unsupported). For this reason, in more responsible constructions, including elevations, the edges of the glass panes must be ground or at least blunted [2,3].

The above drawbacks can be minimized by the use of glass with improved mechanical properties, above all tempered and laminated [4,5]. Tempered glass (ESG), due to the introduction of a positive compressive pre-tensioning in the production process (in the nearsurface glass layer and around the edge) has several times more bending strength, and above all improved resistance to local temperature variation - this is particularly important for façades, where thermal stresses are a basic problem. Tempered glass has another important feature. Inside the glass mass, some energy is trapped - any crack that propagates to the pre-stretched zone makes the whole glass pane "explode". This is advantageous due to the safety of use - the fragments are small, without sharp edges - but it is a certain technical and economic limitation. Formatting glass sheets (cutting, drilling holes, grinding) must take place before hardening. The sensitivity of tempered glass to scratching has been testing in [6].

Laminated glass (VSG) has even better mechanical and functional properties. Annealed or tempered glass panes are connected by layers of special foil or resin (viscoelastic element), which allows to discharge spot pressure. In the case of destruction, grains of glass remain stuck to the foil - the glass is therefore safe for use. Strength tests of laminated panes are presented in [7], damage modeling in [8,9], testing of different connections types of VSG in [10].

Glass panes in glass façades can be used as single panes or as an insulating glass unit (IGU) - at least two panes tightly connected on the edges.

In the context of functionality, a glass façade can be:

- a transparent external building partition, meeting specific thermal protection requirements; in this case, only IGUs are used in principle,

- a structure fixed to an opaque wall or being a stand-alone structure; in this case, the façade has a protective function or improves aesthetics - mostly single panes,

- a "double-skin" structure: the inner layer is formed by a glass curtain wall with IGUs filling, spreading between the ceilings, the outer layer is filled with single panes.

In the structural analysis and strength calculations, the glass is treated as a filling - the supporting structure is responsible for transfer of loads from glass panes to the ground or building elements. In this context, the façades can be divided into three main types:

- post-and-beam façades - panes are embedded in the frame supporting structure, through flexible washers and gaskets,

- structural glazing systems - IGUs are glued on the edges, often through the so-called stepping edge, for the supporting structure with silicone adhesive, experimental tests on adhesives for structural glass-metal connections are presented in [11]

- point supported glass façade (PSGF) - glass panels are connected to the supporting structure with point connectors, the ends of which are placed through holes drilled in the glass.

For the safety of the structure, the design of a suitable connector is therefore one of the important elements.

\section{Kinds of connectors to point fixings}

According to the article [12], point fixings of glass can be divided into through-hole and hole-free ones.

Hole-free fixings are rarely used in large-area façades as an element responsible for load transfer - an embedded cable support (ECS) system described in [13] can be mentioned 
here. They are sometimes used as additional protection, for example with structural glazing. Elements of this type of connections are rings or clamp holders, plate holders glued to the glass and conical heads mounted in the glass mass - a new solution involving inserting metal inserts into the laminate is presented in [14]. Clamping boundary holders are used often, for economic reasons, to attach small elements (e.g. balustrades, shop windows). The use of hole-free connectors therefore requires responsibility, especially if the connection is outside the building. Examples of falling of massive panes fixed only with clamping holders are presented in the article [15].

Therefore, in glass façades commonly used are through-hole fixings, where the elements directly shaping the point support of the glass are the bolted connections called routels. A routel usually consists of a threaded pin, plate holders and an elastic washer that prevents metal-glass contact. The routels are placed in holes drilled in the glass. In the case of IGUs, the holes are most often drilled through all panes of the unit. A combination method is also possible: only the internal pane has the point support, while the external pane is glued, as in the case of structural glazing.

In the case of uncomplicated façades, the rotula can be fixed directly to the supporting structure, but more often this connection is made by intermediate elements. In this group most often used are connectors called, because of their characteristic shape, "spiders". A typical "spider" consists of a roulet and a connector corps attached to the structure. The number of spider's arms is usually from 1 to 4 , but even eight-arm ones are offered for more complicated connections. "Spiders" can be constructed as:

- joint-type connectors - they allow for a small rotation of the pane during operation, for example in the case of structures particularly exposed to wind; the swivel (or the so-called semi-restrained supporting) may be present as an element of routel or at the interface between the connector and the supporting structure.

- rigid connectors - used when more stability is needed.

A review of the methods of analysis and design of connectors used in glass façades is presented in [16]. The design of point connectors mainly consists of evaluation of the boundary load-bearing capacity. In addition, the component is intended to work in the elastic range, because deformations in the plastic range may cause unsealing of façade elements or glass cracking.

In literature, the numerical models based on the finite element method (FEM) are mainly used to determine the static quantities in point connectors. For example, in a twopart article [17, 18] the authors analyzed the glass panes fixed with the connector in different variants of the boundary conditions of the support and compared the numerical results with the ones obtained experimentally. Despite some differences in the results (overrigid numerical model), the usefulness of numerical models has been demonstrated.

Extensive numerical tests (FEM) of point fixed glass façades are shown in [19], experimental and numerical investigations on bearing capacity in [20,21], investigations on the fracture mechanism under various wind speeds combined with fire in [22], study of lifetime of the bolted connections [23] study of support flexibility in the conditions of blast in [24], influence of corner and edge distance of point fixings on glass structures in [25]. In article [26], the authors attempted to optimize the shape of the bolted connections elements, and in [27] the shape of the "spider" type connector.

\section{Purpose and methodology of research}

The purpose of the research presented in the paper is to analyze the applicability of the authors' solution - a double-arm point type "spider" - in the context of its effective work in the structure. 
A similar analysis for a single-arm connector was presented in the article [28], which showed that coupling the walls of the connector corps with a single bolt allows to reduce the maximum stress in this connector, compared to the model without bolts or with two bolts. For this reason, a single bolt was also used in the double-arm connector model. However, the geometry of the connector was slightly changed, due to the different position relative to the edge of the supported glass pane - the single-arm connector was oriented at the angle of $45^{\circ}$ to the edge. It was also assumed that the connector is made of steel of grade S335JR (S235JR is provided for single-arm connector). The S335JR steel has a higher strength, which has a beneficial effect on the rigidity of fixing. The mechanical properties of this steel are shown in Table 1, chemical composition in Table 2.

The analysis was carried out using the ADINA software based on MES. A numerical model of a single, double-arm "spider", fixed in a supporting structure, with a quarter part of a rectangular glass pane attached to both sides was developed. The glass panes were subjected to the dynamic effect of wind gusts (alternately pressure and suction).

Table 1. The mechanical properties of grade S355, [29]

\begin{tabular}{|c|c|c|c|c|c|c|c|c|c|c|c|c|c|c|}
\hline \multirow{3}{*}{ 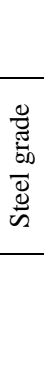 } & \multicolumn{6}{|c|}{$\begin{array}{c}\text { Minimum yield strength Reh } \\
{[\mathrm{MPa}]}\end{array}$} & \multirow{2}{*}{\multicolumn{2}{|c|}{\begin{tabular}{|c|}
$\begin{array}{c}\text { Tensile strength } \\
\text { Rm [MPa] }\end{array}$ \\
Nominal \\
thickness \\
{$[\mathbf{m m}]$}
\end{tabular}}} & \multirow{2}{*}{\multicolumn{4}{|c|}{\begin{tabular}{|c} 
Minimum elongation - A \\
Lo = 5.65 $* \sqrt{\text { So }}(\%)$
\end{tabular}}} & \multicolumn{2}{|c|}{ Notch impact test } \\
\hline & \multicolumn{6}{|c|}{$\begin{array}{l}\text { Nominal thickness } \\
{[\mathrm{mm}]}\end{array}$} & & & & & & & $\begin{array}{l}\text { Tempe } \\
\text { rature }\end{array}$ & $\begin{array}{c}\text { Min. } \\
\text { absorbed } \\
\text { energy }\end{array}$ \\
\hline & $\leq 16$ & $\begin{array}{l}>16 \\
\leq 40\end{array}$ & $\begin{array}{l}>40 \\
\leq 63\end{array}$ & $\begin{array}{l}>63 \\
\leq 80\end{array}$ & $\begin{array}{l}>80 \\
\leq 100\end{array}$ & $\begin{array}{l}>100 \\
\leq 125\end{array}$ & $\begin{array}{c}>3 \\
\leq 100\end{array}$ & $\begin{array}{l}>100 \\
\leq 125\end{array}$ & $\begin{array}{l}>3 \\
\leq 40\end{array}$ & $\begin{array}{l}>40 \\
\leq 63\end{array}$ & $\begin{array}{l}>63 \\
\leq 100\end{array}$ & $\begin{array}{l}>100 \\
\leq 125\end{array}$ & {$\left[{ }^{\circ} \mathrm{C}\right]$} & {$[\mathrm{J}]$} \\
\hline 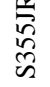 & 355 & 345 & 335 & 325 & 315 & 295 & $470-630$ & $450-600$ & 22 & 21 & 20 & 18 & +20 & 27 \\
\hline
\end{tabular}

Table 2. The chemical composition of grade S355, [29]

\begin{tabular}{|c|c|c|c|c|c|c|c|c|c|c|c|c|c|}
\hline & \multicolumn{13}{|c|}{ Ladle analysis } \\
\hline \multirow[t]{3}{*}{$\begin{array}{l}\text { Steel } \\
\text { grade }\end{array}$} & \multicolumn{3}{|c|}{$\begin{array}{c}\mathrm{C} \\
\max . \\
{[\%]}\end{array}$} & $\begin{array}{c}\mathrm{Mn} \\
\max . \\
{[\%]}\end{array}$ & $\begin{array}{c}\mathrm{Si} \\
\max . \\
{[\%]}\end{array}$ & $\begin{array}{c}\mathrm{P} \\
\max . \\
{[\%]}\end{array}$ & $\begin{array}{c}\mathrm{S} \\
\max . \\
{[\%]}\end{array}$ & $\begin{array}{c}\mathrm{N} \\
\max . \\
{[\%]}\end{array}$ & $\begin{array}{c}\mathrm{Cu} \\
\max . \\
{[\%]}\end{array}$ & $\begin{array}{l}\text { Other } \\
\max . \\
{[\%]}\end{array}$ & \multicolumn{3}{|c|}{$\begin{array}{l}\text { CEV } \\
\max . \\
{[\%]}\end{array}$} \\
\hline & \multicolumn{3}{|c|}{$\begin{array}{c}\text { Nominal thickness } \\
{[\mathrm{mm}]}\end{array}$} & & & & & & & & \multicolumn{3}{|c|}{$\begin{array}{c}\text { Nominal thickness } \\
{[\mathrm{mm}]}\end{array}$} \\
\hline & $\leq 16$ & $\begin{array}{l}>16 \\
\leq 40\end{array}$ & $>40$ & & & & & & & & $\leq 30$ & $\begin{array}{l}>30 \\
\leq 40\end{array}$ & $\begin{array}{l}>40 \\
\leq 125\end{array}$ \\
\hline S355JR & 0.24 & 0.24 & 0.24 & 1.60 & 0.55 & 0.040 & 0.040 & 0.012 & 0.55 & - & 0.45 & 0.47 & 0.47 \\
\hline
\end{tabular}

\section{Numerical model - calculation assumptions}

The dimensions of the analyzed double-arm "spider" connector are shown in Fig. 1, where the letter "a" describes the M8 bolts [30] placed at a distance of $75 \mathrm{~mm}$ from the vertical centre line. As mentioned above, the connector is made of steel S335JR with density $\rho=$ $7850 \mathrm{~kg} / \mathrm{m}^{3}$, Young's modulus is $\mathrm{E}=210 \mathrm{GPa}$, Poisson's ratio $v=0.30$. The S335JR steel was declared in the ADINA as an isotropic and linearly elastic material. It was assumed that the load on a double-arm steel connector is transferred through glass panel of façade with the dimensions $1.5 \times 2.5 \mathrm{~m}$. Due to the assumed symmetry, it is assumed that the load 
is transferred to the connector from the glass fragment with the dimensions $0.75 \times 1.25 \mathrm{~m}$, both heads of a double-arm steel connector (Fig. 2). The glass façade panel was also modelled as isotropic and linearly elastic material with the following parameters: $\mathrm{E}=70$ $\mathrm{GPa}, v=0.23, \rho=2500 \mathrm{~kg} / \mathrm{m}^{3}[5]$.

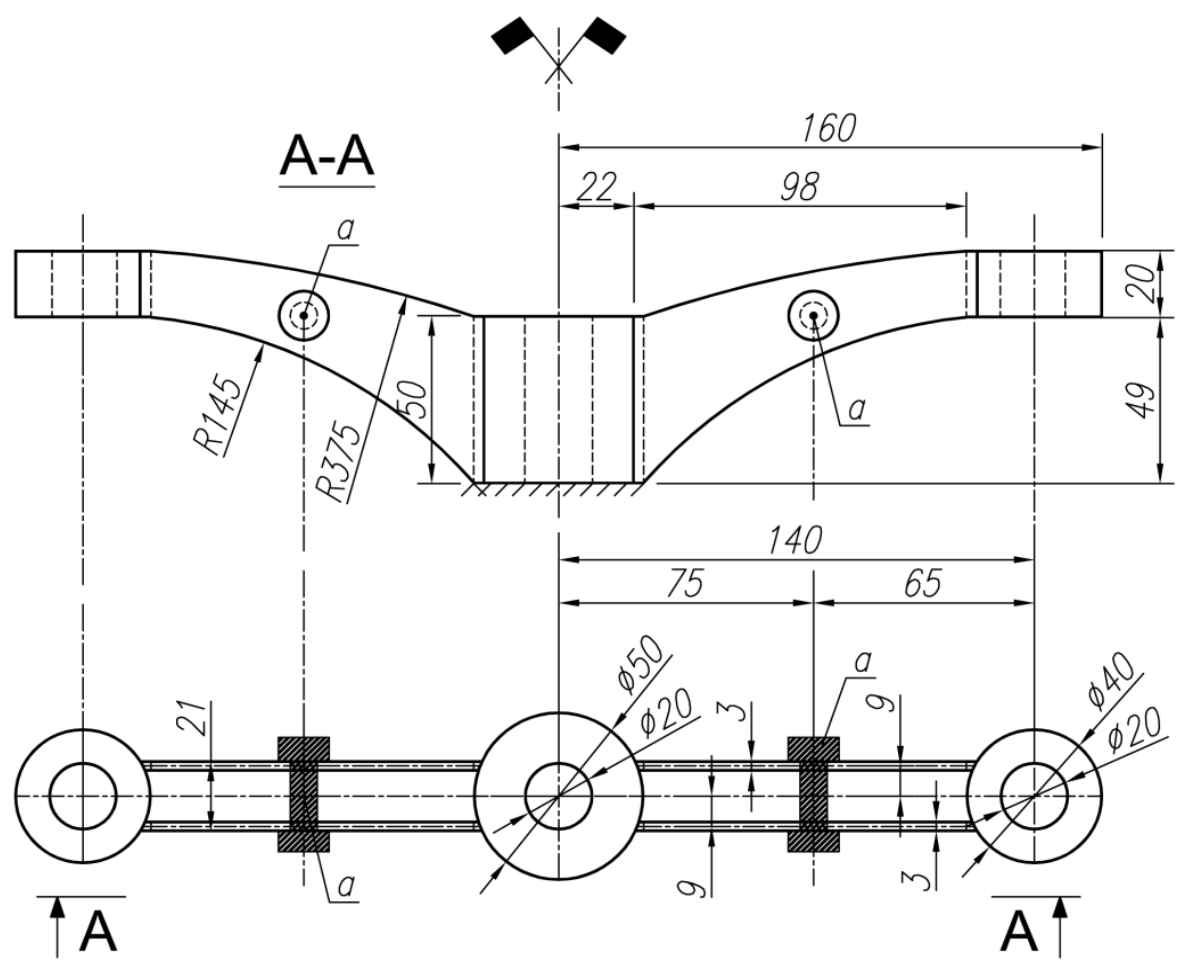

Fig. 1. Considered model of double-arm "spider"

The steel bolt of the connection was modelled without division between the pin, washer and nut. The adopted bolt model is therefore a coherent whole. Potential inaccuracies resulting from welding of steel walls to the bushing were neglected. The numerical model has the following boundary conditions: bushing with the diameter of $\varnothing 50$ has been reinforced at the bottom (Fig. 1), which takes six degrees of freedom as a result of the assumption. The upper surface of the bushing with the diameter of $\varnothing 40 \mathrm{~mm}$ is the place where the connection of the glass pane to the steel connector is made. In the analyzed type of fixing, the glass pane is connected via upper and lower plates and rubber washers placed between bolt, plates and glass. It was assumed that rubber washers compensate for the stresses related to inaccurate manufacture or assembly, and also allow reducing the stress that can arise for short-term dynamic effects at the point of contact of metal elements with the glass pane. 


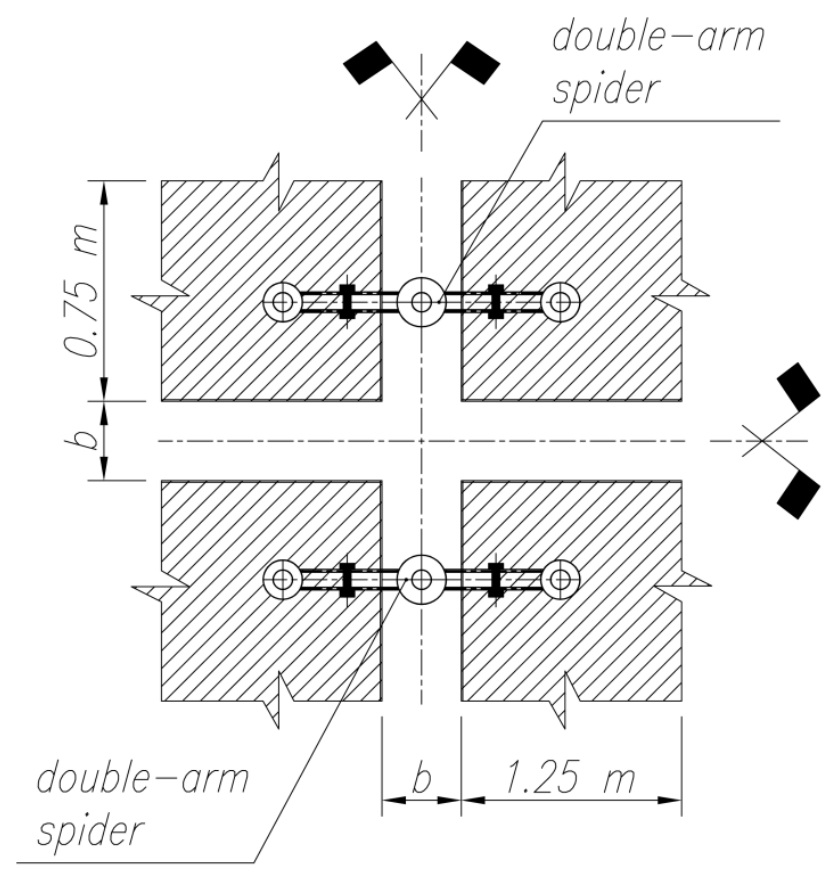

Fig. 2. View of the connection of the glass façade using a double-arm "spider"

The load applied to the upper surface of the glass pane was assumed on the basis of [31], assuming that the glass façade is located in the second wind load zone. It was also assumed that the glass façade has height of up to $100 \mathrm{~m}$ and the land is of fourth category. To determine the maximum wind pressure and suction, the coefficients were determined assuming the effect of wind on A zone. The maximum wind pressure value was calculated, which is $1736 \mathrm{~Pa}$ and the maximum suction pressure equal to $1240 \mathrm{~Pa}$. In an effort to dynamically account for the wind gusts, a sinusoidal load curve was applied. The maximum suction value occurred for time $\mathrm{t}=0.34 \mathrm{~s}$, while the maximum pressure value for time $\mathrm{t}=$ $0.78 \mathrm{~s}$. For the glass panel it was assumed that there are symmetrical boundary conditions on its side walls, i.e. at one of the walls, displacements on the $\mathrm{X}$ axis and rotations with respect to the $\mathrm{Y}$ and $\mathrm{Z}$ axes were blocked, while $\mathrm{Y}$ displacements and rotations with respect to the $\mathrm{X}$ and $\mathrm{Z}$ axes have been blocked respectively on the second wall. The glass panes have been fixed to the connector in accordance with Fig. 2. Discretization of the area of the connector and the glass panes was made on the basis of 4-node "3D-Solid" type elements, declaring the density of the connector and glass plate mesh at the level of $\sim 0.005 \mathrm{~m}$, while on the outer edges of the glass panes the mesh density was reduced to $0.05 \mathrm{~m}$.

\section{Discussion of results}

In order to read the results of stress and displacement, data reading locations were defined, as shown in Fig. 3.

Global displacement at wind pressure was read from the lower point of the upper bushing $\varnothing 40 \mathrm{~mm}$, while at the suction the reading was made from the upper point. The maximum stress was read at the connection of the upper bushing with the steel wall. 


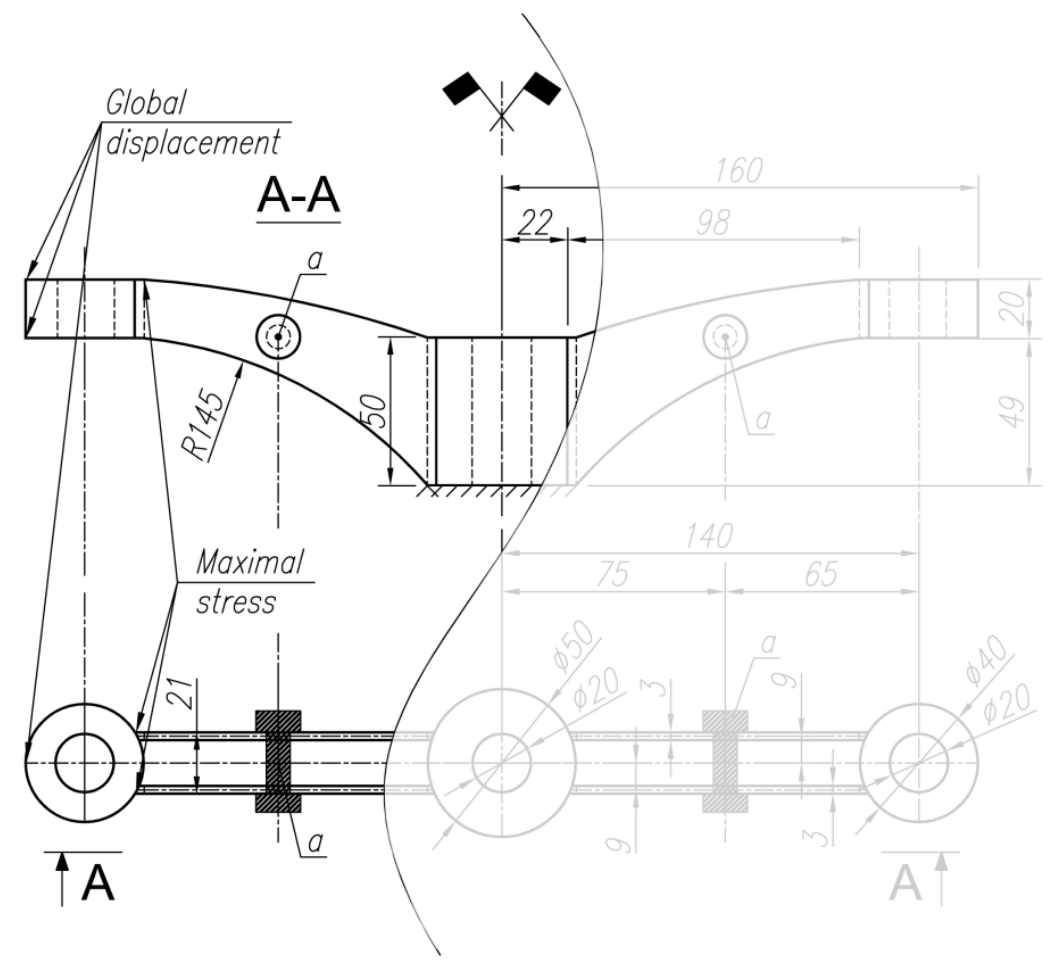

Fig. 3. Global displacement and maximum stress read points

As mentioned, in [28] it has been shown that the use of a single bolt allows to reduce the maximum stress. The results of the maximum stress calculations for wind pressure and wind suction as well as global displacement for the double-arm steel connector considered in the paper are presented in Table 3.

Table 3. Displacement and effective stress values for wind pressure and suction

\begin{tabular}{|c|c|c|c|}
\hline & Unit & $\begin{array}{c}\text { Pressure } \mathbf{t}=\mathbf{0 . 7 8} \mathbf{~ s} \\
\text { Average }\end{array}$ & $\begin{array}{c}\text { Suction } \mathbf{t}=\mathbf{0 . 3 4} \mathbf{~ s} \\
\text { Average }\end{array}$ \\
\hline $\begin{array}{c}\text { Global } \\
\text { displacement }\end{array}$ & {$[\mathbf{m m}]$} & -0.09193 & 0.0687 \\
\hline Maximal stress & {$[\mathbf{M P a}]$} & 109.23 & 78.93 \\
\hline
\end{tabular}

On the basis of the results presented in Table 3, it can be stated that the designed double-arm connector used for fixing the glass façade meets the structural requirements, when using S355JR steel. This paper concerns the numerical analysis of the connector, so the stresses and deformations of the glass plate are not shown here. The susceptibility of connecting the bushing to the supporting structure was also not considered. The solution presented on the basis of numerical analysis allowed to determine both vertical displacements as well as stresses. Undoubtedly, the use of M8 bolts as in the solution described in [28] improves the effectiveness of the presented solution.

Considering the values of reduced stresses presented in Fig. 4, the symmetry of stress distribution at wind pressure is clearly visible. Also, the reduced stresses at wind suction 
will be symmetrical with respect to the vertical axis passing through the central bushing with a diameter of $50 \mathrm{~mm}$.

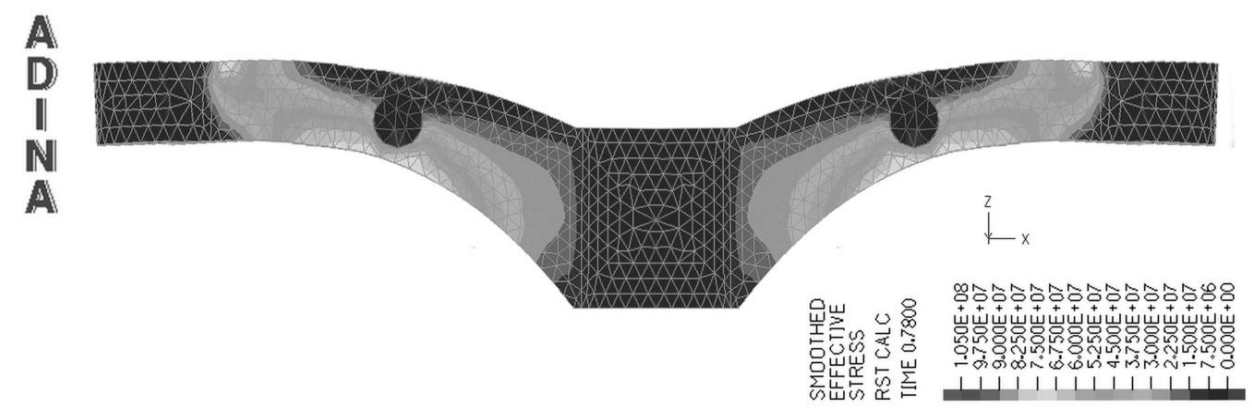

Fig. 4. Distribution of reduced stresses at wind pressure for $t=0.78 \mathrm{~s}$

\section{Conclusions}

The analysis of the literature carried out in this papers has shown that "spider" connectors belong to the most frequently used point fixings of glass façades. The analyzed double-arm connector, with the adopted geometry, is one of many possible solutions in this regard. It has a simple and economical design: three bushings connected with each other in the form of double steel walls. To this basic construction, a modification was carried out consisting in coupling the walls of the corps with a single M8 bolt. As shown in the previous analysis of the single-arm connector [28], a single bolt not only allows for better symmetry of load transfer, but also for obtaining lower values of stresses in the steel walls of the connector. Undoubtedly, the authors' model of a double-arm connector with a single bolt from an economic point of view does not cause major difficulties in the production phase, as well as assembly, and allows to obtain a symmetrical stress distribution and limits global displacement.

In relation to the single-arm connector analyzed in [28], two more modifications were introduced: a slight correction of geometrical dimensions and a change in the steel grade. Both of these modifications are related to the different positioning of the double-arm connector (perpendicular to the edge of glass pane) than the single-arm (at an angle of $45^{\circ}$ ). A small bolt offset improves the efficiency of the connector. The used S335JR steel has a higher strength and less formability than S235JR steel. The characteristics of the steel thus strongly influences the operating parameters of the connector, which was obtained at the stage of numerical simulation.

The numerical analysis of maximum stresses at wind pressure and suction as well as global displacement has shown that the proposed solution is applicable in the context of construction safety for the height of glass façades up to $100 \mathrm{~m}$. Of course, the use of modified connectors in the real structure should be preceded by appropriate experimental research.

\section{References}

1. F. Pariafsain, Frontiers of Architectural Research, 5, 171-193 (2016)

2. D. Jaśkowska, Świat Szkła, 3, 128, 20-23 (2009)

3. L.B. Klindt, W. Klein, Glas als Baustoff. Eigenschaften, Anwendung, Bemessung, Verlagsgesellschaft R. Müller, Köln-Braunsfeld (1997)

4. Z. Respondek, Advanced Materials Research, 583, 195-198 (2012) 
5. Glas und Praxis, Kompetentes Bauen und Konstruieren mit Glas, Glas Trösch Holding AG, Beratung, Bützberg (2012)

6. J. Schneider, S. Schula, W.P. Weinhold, Thin Solid Films, 520, 4190-4198 (2012)

7. G. Sedlacek, K. Blank, Glas im Konstruktiven Ingenieurbau Ernst \& Sohn, Berlin, (1999)

8. M. Teotia, R.K. Soni, Engineering Failure Analysis, 94, 412-437 (2018)

9. A. Vedrtnam, S.J. Pawar, Engineering Fracture Mechanics, 186, 316-330 (2017)

10. X. Centelles, J.R. Castro, L.F. Cabeza, Engineering Structures, 180, 192-204 (2019)

11. B. Van Lancker, J. Dispersyn, W. De Corte, J. Belis, Engineering Structures, 126, 237251 (2016)

12. Z. Czajka, Świat Szkła, 6, 120, 30-34 (2008)

13. Y. Wang, Z. Wang, K. Xu, Y. Shi, X. Du, Engineering Structures, 178, 521-533 (2019)

14. M. Santarsiero, C. Bedon, C. Louter, Composite Structures, 188, 242-256 (2018)

15. Z. Respondek, Glass building elements - technical aspects of safe usage in the structure, 7th International Conference System Safety: Human - Technical Facility Environment (2018)

16. C. Bedon, X. Zhang, F. Santos, D. Honfi, M. Kozłowski, M. Arrigoni, L. Figuli, D. Lange, Construction and Building Materials, 163, 921-937 (2018)

17. B. Szczerbal, D. Włochal, A. Glema, T. Łodygowski, Świat Szkła, 4, 129, 24-26 (2009)

18. B. Szczerbal, D. Włochal, A. Glema, T. Łodygowski, Świat Szkła, 6, 131, 34-37 (2009)

19. C. Bedon, C. Amadio, Engineering Structures, 112, 233-244 (2016)

20. Y. Wang, H. Yuan, Y. Shi, Y. Zou, International Journal of Steel Structures, 2, 12, 191-204 (2012)

21. Z. Wang., Y. Wang, Y. Liang, X. Du, Y. Shi, Archives of Civil and Mechanical Engineering, 16, 935-948 (2016)

22. W. Lu, Y. Wang, H. Chen, L. Jiang, Q. Duan, L. Li, Q. Wang, J. Sun, Construction and Building Materials, 186, 635-643 (2018)

23. J. Watson, J. Nielsen, M. Overend, Engineering Structures, 57, 87-99 (2013)

24. H.D. Hidallana-Gamage, D.P. Thambiratnam, N.J. Perera, Construction and Building Materials, 154, 462-481 (2017)

25. J. Dispersyn, J. Belis, J. De Jaegher, Engineering Structures, 105, 174-185 (2015)

26. F. Bernard, L. Daudeville, Engineering Structures, 31, 946-955 (2009)

27. K. Kuliński, J. Selejdak, M. Major, Quality Production Improvement, 1, 6, 47-56 (2017)

28. I. Major, M. Major, Z. Respondek, Archives of Metallurgy and Material, 63, 1, 491496 (2018)

29. Polish standard - EN 10025-2:2004- Hot rolled products of structural steels - Part 2: Technical delivery conditions for non-alloy structural steels

30. EN-ISO 4014:2011 Hexagon head bolts - Product grades A and B

31. Polish standard - EN 1991-1-4:2005/A1:2010 Eurocode 1: Actions on structures Part 1-4: General actions - Wind actions 